\section{'Goodwin' Peach: a Processing Clingstone Peach Ripening in the 'Dixon'-'Andross' Maturity Season}

\author{
Thomas M. Gradziel ${ }^{1}$ and Mary Ann Thorpe \\ Department of Plant Sciences, One Shields Avenue, University of California, \\ Davis, CA, 95616
}

Additional index words. variety breeding, Canning peach, Prunus persica, anthocyanin staining, fresh market

'Goodwin' peach [Prunus persica (L.) Batsch] produces a clingstone, non-melting fruit suitable for processing or fresh market. Evaluated as selection R7-5, it was derived from a cross between 'Dr. Davis' and breeding selection '11,11-37', which has 'Dixon', 'Elberta', and PI 292557 in its lineage. Ripening time is during the commercially important period between 'Dixon' and 'Andross', being $\approx 3 \mathrm{~d}$ before 'Fay Elberta'. In long-term commercial evaluations, fruit have demonstrated very good processing quality and remained free of the undesirable red anthocyanin staining of fruit flesh as occurs in many cultivars of this maturity. Fruit possess good firmness and color and are slightly oval in shape. Trees have proven to be consistently productive in over 10 years of continuous commercial evaluation in environments having $700 \mathrm{~h}$ or more of winter chilling. Tree form is semiupright with vigor and branch architecture similar to 'Andross'. Flowers are pink, non-showy, and medium in size. Leaves are medium to dark green with reniform leaf glands.

\section{Origin}

The University of California at Davis has maintained a processing peach [Prunus persica (L.) Batsch] breeding program since the 1980 s with the support of the California cling peach growers and processors. The initial objective of the breeding program was to replace early maturity season cultivars Dixon and Andross and the late-season cultivar Halford. 'Dixon', introduced in 1956, was one of the first "extra-early maturity" season cultivars that could consistently achieve commercially profitable yields when thinned to achieve desired fruit sizes of $60.33 \mathrm{~mm}$ or greater. Fruit flesh was a desirable yellowgold and possessed good fresh and processed eating quality, but the fruit pit cavity often developed a pink to red color from the formation of red anthocyanins. The anthocyanins oxidized to brown when heat-processed, staining both the processed fruit and syrup.

Received for publication 10 July 2007. Accepted for publication 31 Aug. 2007.

${ }^{1}$ To whom reprint requests should be addressed; e-mailtmgradziel@ucdavis.edu.
The 'Dixon' fruit endocarp or stone was also more prone to breakage, resulting in pit fragments in processed fruit. Because of these problems, processors discontinued 'Dixon' fruit purchases and this cultivar is no longer being commercially planted, although no replacement cultivar presently exists (Fig. 1). 'Andross' was developed as a source of fruit for processors during the 'Early Maturity' season after 'Dixon' production. 'Andross' originated from a cross with 'Dixon' as a grandparent and was introduced in 1964. 'Andross' has become the most heavily planted cultivar for the "early" maturity season owing primarily to its proven potential to produce firm fruit of good commercial size. 'Andross', however, also produces fruit with frequent red staining of the pit and pit fragments in processed fruit. The resultant

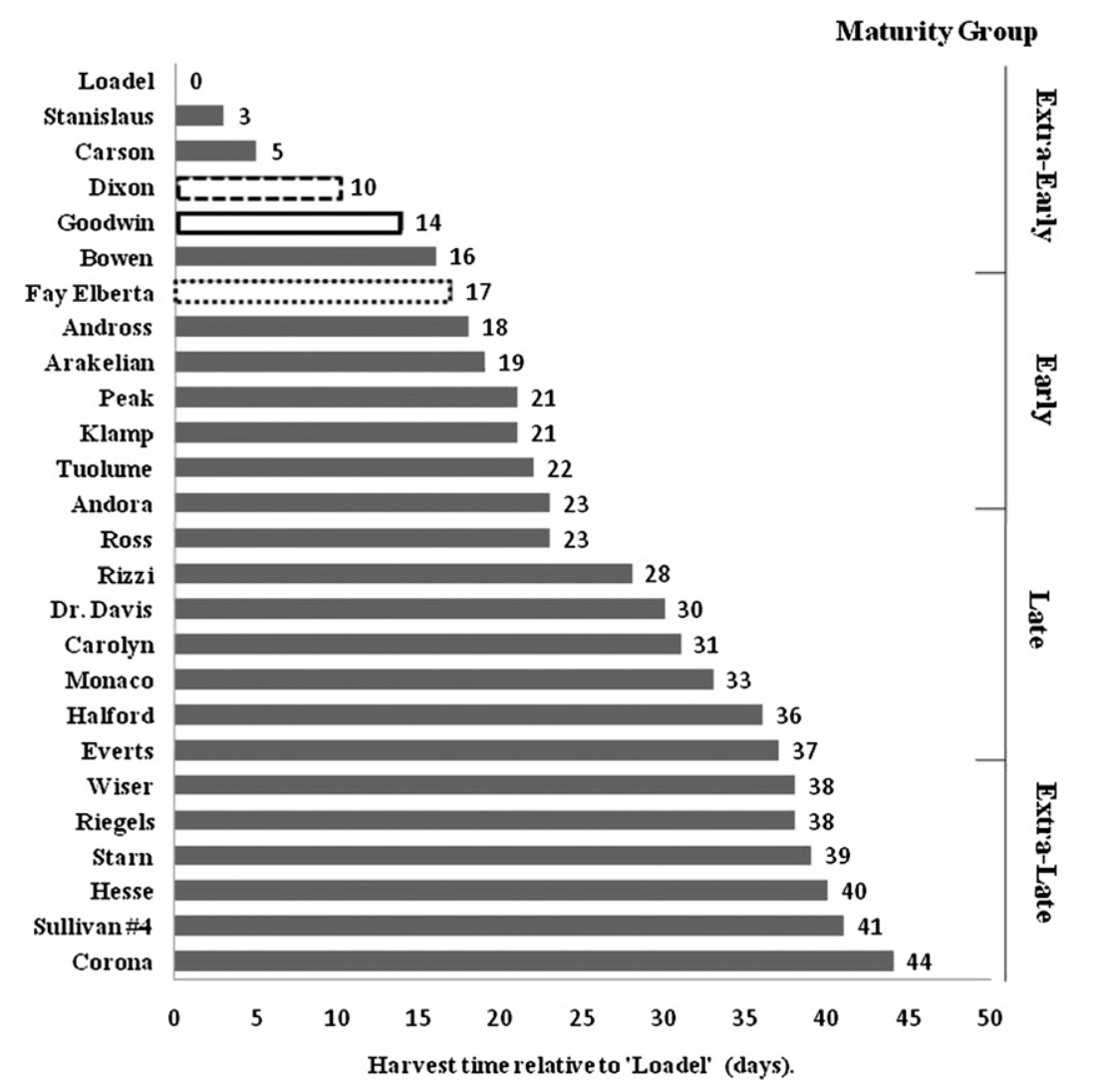

Fig. 1. Fruit maturity time of 'Goodwin' relative to other canning clingstone peaches in California. (Freestone cultivar Fay Elberta included as a reference.). low case yields have led processors to discourage new plantings of this cultivar and indicates that they may need to discontinue purchases of fruit of this cultivar in the future. 'Bowen', the only remaining cultivar ripening in this season (Fig. 1), also has 'Dixon' as a grandparent and has never achieved high plantings as a result of inferior fruit quality and yields. Pedigree analysis has documented extensive use of Dixon as well as a sibling selection designated 'Dixon\#2' in cultivar development efforts before the 1980s (Gradziel et al., 1993). With the release of the UC Davis cultivars Dr. Davis and Ross in the mid1980 s, new yet highly adapted germplasm derived from the germplasm PI292557 and the freestone cultivar Elberta was made available for continued genetic improvement. Because of their high fruit quality and yield potential, 'Dr. Davis' and 'Ross' have become the most extensively planted processing peaches in California and have come to represent a quality/yield standard for future cultivars. 'Goodwin' is a product of a breeding effort to combine desirable traits of 'Dixon' and 'Dr. Davis'. It is the result of a controlled cross between UC processing peach breeding line '11.11-37' as the female (seed) parent and the UC processing peach cultivar Dr. Davis as the male (pollen) parent (Fig. 2). Originally designated as seedling 'R.7-5', it was selected based on its good fruit and tree qualities, its freedom from red staining of the pit, the low frequency of pit fragments in processed flesh, and its desirable ripening time of $4 \mathrm{~d}$ before the cultivar Andross. Regional evaluation 


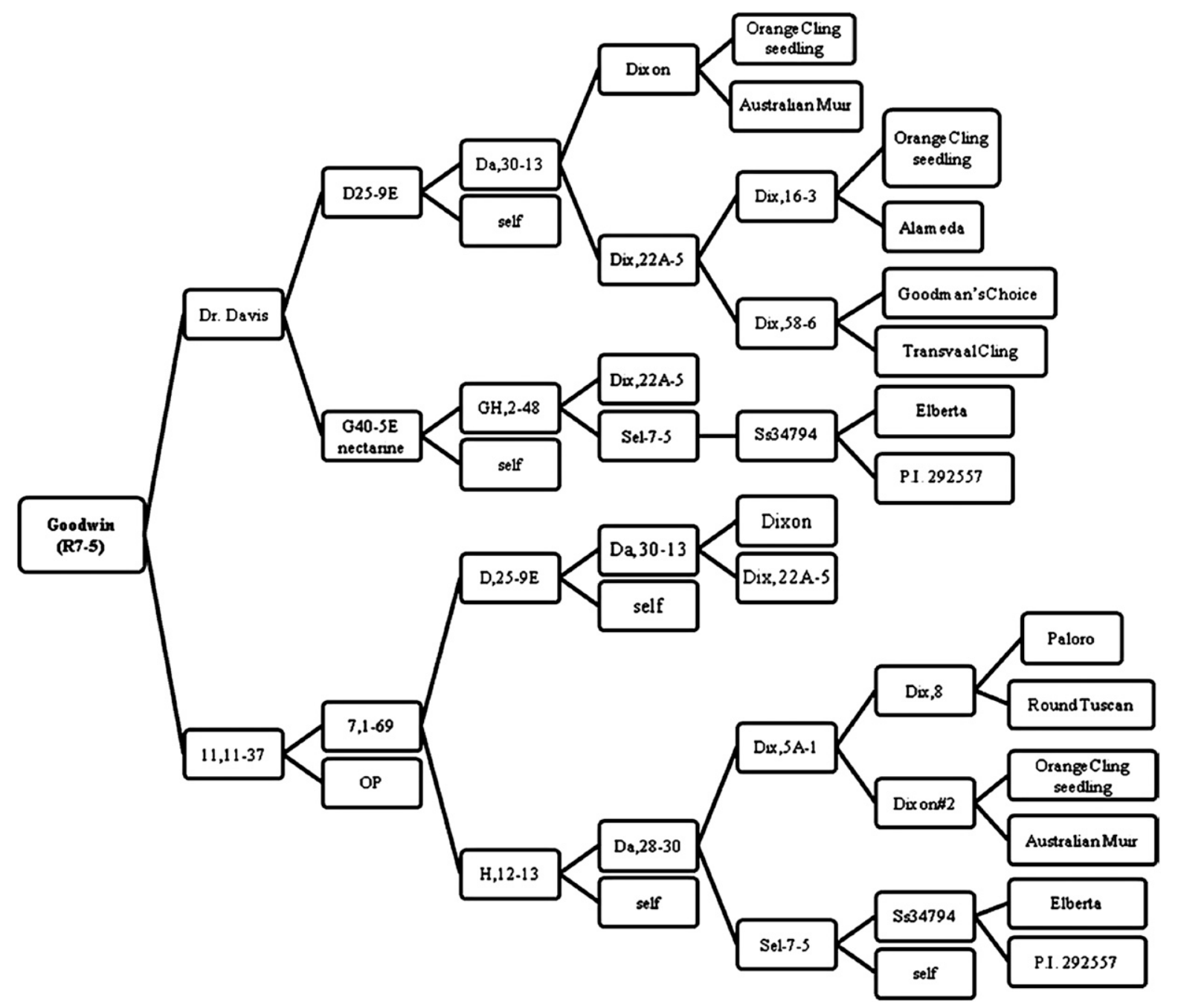

Fig. 2. Pedigree of 'Goodwin' peach. Seed parent is presented at the top.

plots for 'R.7-5' were established in 1992 at Winters and Davis, CA, in the Sacramento Valley and at Parlier, CA, in the San Joaquin Valley and in 1998 at multiple grower evaluation plots in the Sacramento and San Joaquin Valleys. Based on its very positive evaluations, selection 'R.7-5' has been patented and released as the processing peach cultivar Goodwin after Mr. Ray Goodwin, a Del Monte plant manager who was very supportive of the early breeding program.

\section{Description}

'Goodwin' produces processing clingstone peach fruit, which ripen during the commercially important period between 'Dixon' and 'Andross'. Fruit is medium in size, being slightly ovate to round in shape and with a slight fruit tip. 'Goodwin' remains free from the elongated tip that develops on some clingstone peach cultivars after mild winter and warm spring weather (Fig. 3). Flesh is bright yellow to yellow-gold. Fruit skin is slightly less pubescent than 'Andross' with a more uniform golden yellow color. Pit is medium in size and has remained free from the red color and high pit fragments of 'Dixon' and 'Andross' even in environments promoting this condition. The tree is semiupright with vigor similar to 'Andross'. Branch architecture is similar to 'Andross' although often with a denser canopy. Flowers are pink, nonshowy, and medium in size with two flowers commonly present per node. Leaves are medium to dark green, similar in size to 'Andross' but with reniform rather than globose leaf glands.

\section{Performance}

Trees were evaluated from 1996 to 2006 under standard commercial conditions in the Sacramento and San Joaquin Valleys. Trees produce a medium to high crop, comparable to 'Andross', and thus needing less thinning after a high-chill winter but possibly vulnerable to lower crops after low-chill winters. 'Goodwin' bloom was uniform and abundant when chilling hours were above a $700 \mathrm{~h}$ (using the Utah model of Byrne and. Bacon, 1992) as occurred in all Central Valley test sites and years. Bloom time at Central Valley commercial production sites was midseason in relation to other commercial cling peach cultivars, being similar to 'Andross'.
'Goodwin' fruit were fully clingstone and non-melting. Fully ripe fruit, as determined by a lack of visible green pigmentation on the fruit epidermis, showed an orange-yellow primary ground color with from $20 \%$ to $60 \%$ red blush. Fruit skin had a fine, short, and netted pubescence with no observed tendency to crack. Some split pits occur in low crop years although at lower rates than either 'Dixon' or 'Andross'. Fruit flesh (mesocarp) firmness demonstrated a significant improvement over the Andross cultivar, being comparable to the Dixon cultivar (Table 1). Fruit mass was similar to both 'Dixon' and 'Andross' when thinned using recommendations developed for the Andross cultivar (California Canning Peach Association, 2005) to achieve commercial fruit diameters of 60.33 $\mathrm{mm}$ or greater on at least $95 \%$ of fruit. 'Goodwin' fruit were fully acceptable to California processors over the 10-year evaluation period despite fruit being slightly oblate in form when compared with the more symmetrical Dixon and Andross cultivars (Fig. 3). The larger fruit diameter perpendicular to the suture line (Fig. 3) results in more fruit of a given mass exceeding the minimal accepted fruit diameter of $60.33 \mathrm{~mm}$ when graded by the industry 


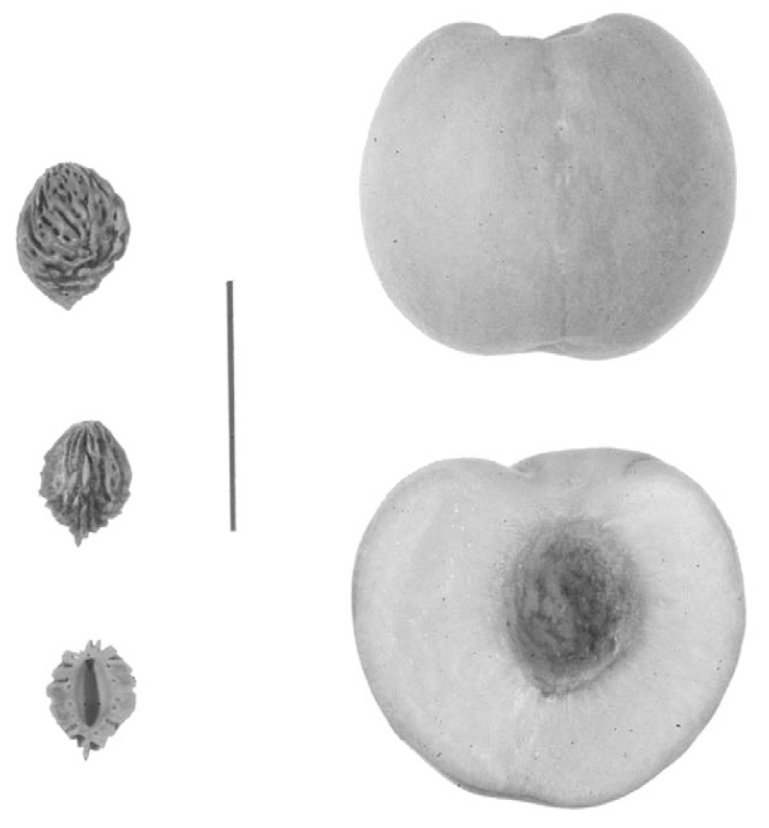

Fig. 3. Leaf, fruit, and stone morphology of 'Goodwin' peach $(\mathrm{bar}=5 \mathrm{~cm})$.

Table 1. Performance of 'Goodwin' clingstone processing peach as compared with the California cultivars Dixon and Andross. ${ }^{\mathrm{z}}$

\begin{tabular}{lcrr}
\hline & Dixon & Goodwin & Andross \\
\hline Raw fruit size (g fresh weight) & $119.8 \mathrm{a}$ & $124.4 \mathrm{ab}$ & $128.3 \mathrm{~b}$ \\
Raw fruit firmness (kg)" & $3.6 \mathrm{ab}$ & $3.7 \mathrm{~b}$ & $3.3 \mathrm{a}$ \\
Processed flesh color "a" value & $4.8 \mathrm{a}$ & $4.4 \mathrm{a}$ & $5.5 \mathrm{a}$ \\
Processed flesh color "hue" value & $79.3 \mathrm{a}$ & $80.3 \mathrm{a}$ & $81.2 \mathrm{a}$ \\
Proportion with red staining & $0.92 \mathrm{c}$ & $0.0 \mathrm{a}$ & $0.74 \mathrm{~b}$ \\
Proportion with shell fragments & $0.68 \mathrm{c}$ & $0.02 \mathrm{a}$ & $0.34 \mathrm{~b}$ \\
\hline
\end{tabular}

${ }^{2}$ Mean separation performed within each row by Duncan's multiple range test $(P=0.05)$ from a sample size of 50 fruit randomly harvested from ninth leaf trees thinned to achieve commercial size of 60.33 or greater in $95 \%$ of fruit.

${ }^{\mathrm{y}}$ Fruit firmness was measured with a Magness-Taylor firmness tester using an 8-mm tip with fruit epidermis removed.

${ }^{\times}$CIELAB $1976 \mathrm{~L} * \mathrm{a} * \mathrm{~b} *$ color space determined using a Minolta $2000 \mathrm{~L}$ spectrophotometer combined with Minolta WinShades 1.0 color analysis software (Konica-Minolta, Ramsey, NJ).

standard circular sizing ring. In addition, the fruit stem cavity of 'Goodwin' was found to be similar to both the Dixon and Andross cultivars, having the consistently broad and mod- erately deep cavity necessary for the proper alignment of fruit during torque pitting and processing. Processed flesh color "a" and hue values were in the desirable yellow to yellowgold range (Gradziel, 1994; Tourjee et al., 1998), being comparable to both the Dixon and Andross cultivars (Table 1). Unlike 'Dixon' and 'Andross', however, 'Goodwin' showed no tendency toward the development of undesirable red anthocyanin staining of the fruit cavity and significantly fewer fruit with pit fragments in processed fruit. Since its release, 'Goodwin' has become one of the most heavily planted processing clingstone peach cultivars in California, addressing grower and processor needs for a good quality and good sizing peach for the 'Dixon'-'Andross' maturity period.

\section{Availability}

'Goodwin' is available as a patented (US Plant Patent 13911) cultivar with licenses granted through the University of California Technology Transfer Services, 1850 Research Park Drive, Suite 100, Davis, CA 95618-6134. Propagation material is distributed as registered virus-tested sources through the Foundation Plant Service, University of California 1 Shields Avenue, Davis, CA 95616.

\section{Literature Cited}

Byrne, D.H., and T.A. Bacon. 1992. Chilling estimation: Its importance and estimation. The Texas Horticulturist 18:5, 8-9.

California Canning Peach Association. 2005. Cling Peach Almanac. Sacramento, CA. p. 7.

Gradziel, T.M. 1994. Changes in susceptibility to brown rot with ripening in three clingstone peach genotypes. J. Amer. Soc. Hort. Sci. 119: 101-105.

Gradziel, T.M., W. Beres, and K. Pelletreau. 1993. Inbreeding in California canning clingstone peach cultivars. Fruit Varieties J. 47: 160-168.

Tourjee, K.R., D.M. Barrett, M.V. Romero, and T.M. Gradziel. 1998. Measuring flesh color variability among processing clingstone peach genotypes differing in carotenoid composition. J. Amer. Soc. Hort. Sci. 123:433-437. 